\title{
Erratum to: Bodily self: an implicit knowledge of what is explicitly unknown
}

\author{
Francesca Frassinetti - Francesca Ferri • \\ Manuela Maini - Maria Grazia Benassi • \\ Vittorio Gallese
}

Published online: 29 May 2011

(C) Springer-Verlag 2011

\section{Erratum to: Exp Brain Res \\ DOI 10.1007/s00221-011-2708-x}

Unfortunately, Fig. 3a in the original version of this article contains an error. The figure legend (graph key) of the Fig. 3a is wrong. The white bars represent the mean percentages of correct responses (accuracy) for self and the black bars represent the mean percentages of correct responses (accuracy) for others' body-effectors and inanimate-objects in the explicit task. Therefore the correct version of Fig. 3 can be found here.

The online version of the original article can be found under doi:10.1007/s00221-011-2708-x

F. Frassinetti $(\square) \cdot$ M. Maini · M. G. Benassi

Department of Psychology, University of Bologna,

Viale Berti Pichat, 5, 40127 Bologna, Italy

e-mail: francesc.frassinetti@unibo.it

F. Ferri · V. Gallese

Department of Neuroscience,

University of Parma, 43100 Parma, Italy

F. Ferri

ITAB, “G. D’Annunzio" University, Chieti, Italy

\section{Gallese}

Brain Center for Social and Motor Cognition,

Italian Institute of Technology, Parma, Italy
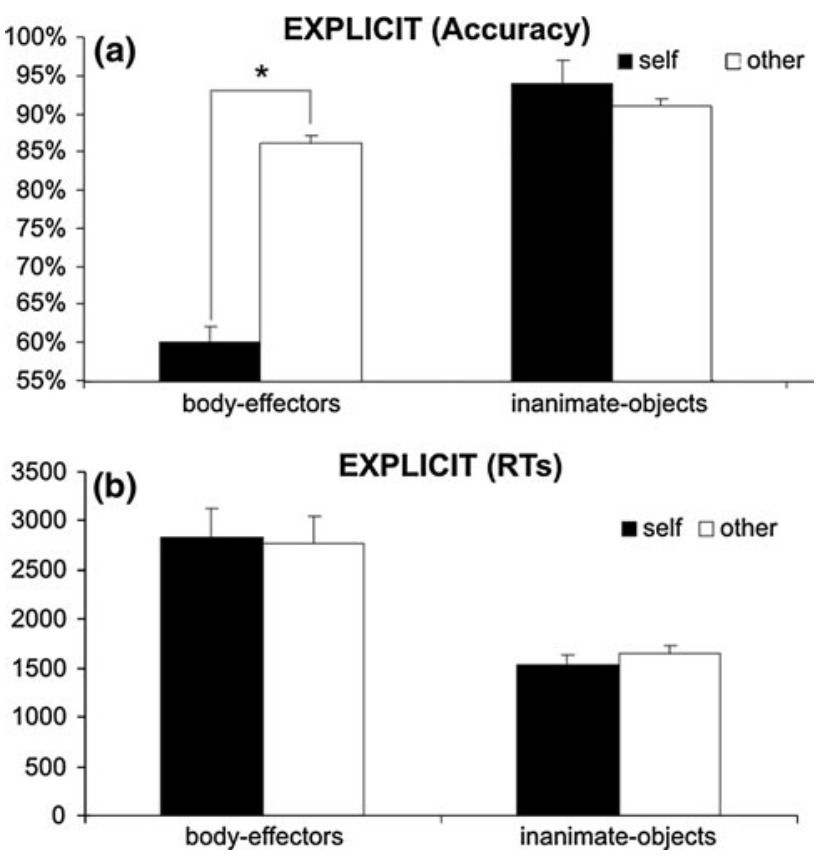

Fig. 3 Mean percentages of correct responses (accuracy) (a) and mean reaction times (RTs) (ms) (b) for self and others' body-effectors and inanimate-objects in the explicit task. Error bars depict the standard error of the mean 